\title{
Bromelain prevented nickel-induced testicular toxicity via suppression of sperm DNA fragmentation and sperm quality alterations in rats
}

\author{
CIGDEM CEBI SEN, FUSUN TEMAMOGULLARI*, NIHAT YUMUSAK**, ADNAN KIRMIT*** \\ Department of Reproduction and Artificial Insemination, *Department of Pharmacology and Toxicology, \\ **Department of Pathology, Faculty of Veterinary Medicine, Harran University, Eyyübiye, Sanliurfa, Turkey \\ ***Department of Biochemistry, Faculty of Medicine, Harran University, Osmanbey, Sanliurfa, Turkey
}

\section{Cebi Sen C., Temamogulları F., Yumusak N., Kirmit A.}

Bromelain prevented nickel-induced testicular toxicity via suppression of sperm DNA fragmentation and sperm quality alterations in rats

\section{Summary}

This study investigated the protective effect of bromelain on sperm quality and DNA, antioxidant system and testis structure in rats with experimentally induced nickel toxicity. Four groups, each of $\mathbf{1 0}$ male Wistar albino rats, were established. One was maintained for control purposes, while the other three received bromelain alone, nickel alone and nickel+bromelain. While bromelain was administered by oral route $(20 \mathrm{mg} / \mathrm{kg})$, nickel sulfate was given intraperitoneally $(20 \mathrm{mg} / \mathrm{kg})$ at alternate days. Nickel exposure significantly reduced relative testicular weight and seminiferous tubule diameter. Nickel exposure also led to significantly decreased antioxidant levels, as well as a negative impact on sperm quality. On the other hand, nickel+bromelain administration increased sperm motility, sperm counts, viable sperm percentage and antioxidant levels, and reduced sperm DNA fragmentation. It was concluded that the administration of bromelain which has antioxidant effect to nickel-intoxicated rats prevented damage to sperm quality and DNA, and the antioxidant system.

Keywords: bromelain, nickel, rat, sperm, testis

Nickel is a ubiquitous environmental heavy metal pollutant. It is also known to be the fifth most common element in the world (20). Owing to its unique physical and chemical properties, metallic nickel and its compounds have a wide range of use in modern industries (15). Nickel can be obtained by metallurgical activities, including mining, refining, electroplating, welding, and the manufacture of stainless steel (7, 15). Nickel is also a major component of alloys found in orthopaedic plate and screw assemblies and is used in the manufacture of artificial organs (12). Research results suggest that nickel could be an essential trace metal that enhances growth in birds and mammals at very low doses (ppb) (14). However, high doses of nickel may show a carcinogenic effect in both humans and animals (14). The exposure of humans and animals to nickel may occur by ingestion, dermal contact, and inhalation (10). Although nickel uptake occurs mostly via food and water consumption, in occupational settings the primary route of nickel-induced toxicity is inhalation (17). In the body, nickel mainly accumulates in the kidneys, lungs, liver and testes and causes tissue damage $(10,20)$, resulting in neurotoxicity, nephrotoxicity, hepatotoxicity, reproductive toxicity, genotoxicity, as well as an increased risk of cancer (10). The reproductive system is known to be more sensitive to hazardous factors such as nickel and other metals that pollute the environment $(7,32)$. Animal research has demonstrated nickel-induced adverse effects on the structure and functions of the testes, seminal vesicles, and prostate gland, as well as on spermatozoa (14). Moreover, research has shown that nickel causes damage to the testicular structure in experimental animals, which is manifested by an increased percentage of abnormal spermatozoa, fragmentation of DNA strands, cell damage, necrosis, cell apoptosis, oxidative stress and the generation of reactive oxygen species (ROS) (32). The toxic and carcinogenic effects of nickel compounds have been well demonstrated in humans and experimental animals, yet the underlying mechanisms of nickel-induced reproductive toxic effects in males remain unclear (6). Animal experiments have demonstrated the occurrence of testicular toxicity and oxidative stress after exposure to high doses of nickel. In 
mice, nickel-induced toxicity is present with increased DNA damage, lipid peroxidation, and apoptosis in the testes, morphological abnormalities of the sperm head and reduced fertility (6). Nickel toxicity can be prevented with the use of antioxidant compounds which are effective against the adverse effects of reactive oxygen and nitrogen species (2).

Bromelain, which is extracted from the stem and fruit of the pineapple plant, has anti-inflammatory, fibrinolytic, proteolytic, antithrombotic, anti-oxidant, and proteolytic effects (28). Bromelain, as a proteolytic enzyme, breaks down proteins and is composed of different thiol endopeptidases and other components including glucosidase, phosphatases, peroxidases, cellulases, carbohydrates, glycoproteins, and protease inhibitors (3). Owing to its pharmacological and biochemical properties, bromelain is recognized as a safe and effective therapeutic agent, and is used worldwide for the treatment of several disorders, including, among others, bronchitis, sinusitis, arthritis and in inflammation, surgical trauma, and thrombophlebitis, as well as for the debridement of wounds, and the enhanced absorption of drugs, particulary antibiotics $(26,27)$. Although how it acts at the molecular level has not been fully elucidated yet, it has been demonstrated that orally administered bromelain is well absorbed in the body, maintains its proteolytic activity and does not cause any major side effects after oral administration (27). Bromelain is absorbed from the human intestines and maintains biological activity with a half-life of $\sim 6-9 \mathrm{~h}$ (18). Research conducted in experimental animals has shown that bromelain has analgesic, antiedematous, anti-inflammatory, anticoagulant, immunomodulatory and hepatoprotective effects (19). However, the impact of bromelain, which is known to have antioxidant properties, on sperm quality and testis damage remains unknown. Thus this study was aimed at the investigation of the possible protective effect of bromelain on sperm quality and testicular structure in rats with induced nickel-induced toxicity.

\section{Material and methods}

Chemicals. Bromelain and nickel sulfate were obtained from Sigma Chemical (St Louis, MO, USA). The percentage of sperm with DNA damage (DFI), sperm membrane integrity and acrosomal integrity was assessed using SpermHalomax-Mus kit (Halotech DNA, Madrid, Spain), fluorescence 'live/dead kit' (Molecular Probes, Eugene, OR, USA), Alexa Fluor-488-PNA (peanut agglutinin) conjugate (Molecular Probes, Eugene, OR, USA), respectively.

Animals and care. Forty male Wistar albino rats, aged 3 months and weighing 200-250 g, were used in this study. The rats included in the study were confirmed to be free from disease and deformity. The rats were acclimatized for one week prior to the start of the study. The animals were kept under standard laboratory conditions (daily light period of $12 \mathrm{~h}$ and temperature of $21^{\circ} \mathrm{C} \pm 2{ }^{\circ} \mathrm{C}$ ), and were provided with ad libitum food and water. The experimental procedures followed were in accordance with the regulations of the Institutional Animal Ethics Committee. Ethics committee approval was received for this study from the ethics committee of Harran University School of Medicine (Date: 05.06.2018, No:13153).

Animal treatment. The rats were randomly allocated to four groups, each with ten animals, including a control group (Group I), and treatment groups that were administered with nickel sulphate alone (Group II), bromelain alone (Group III) and nickel sulphate+bromelain (Group IV). The control animals included in Group I were administered with a daily intraperitoneal dose of $0.2 \mathrm{ml}$ of $0.9 \mathrm{NaCl}$ solution for 21 days. Group II received $20 \mathrm{mg} / \mathrm{kg}$ bw/day of nickel sulphate (dissolved in isotonic saline) alone by intraperitoneal route for a 21 day-period (24). While Group III was given $20 \mathrm{mg} /$ $\mathrm{kg}$ bw/day of bromelain (dissolved in distilled water) alone by oral route for 21 days (1), Group IV received a combination of an oral daily dose of $20 \mathrm{mg} / \mathrm{kg}$ bw of bromelain 6 hours after an intraperitoneal daily dose of $20 \mathrm{mg} / \mathrm{kg}$ bw nickel sulphate for 21 days. Body weights were recorded on the days of treatment and autopsy.

Measurement of total antioxidant levels (TAS). On the $22^{\text {nd }}$ day of the trial, serum total antioxidant levels were measured using commercially available diagnostic kits (RelAssay, Gaziantep, Turkey). The samples were read spectrophotometrically and the results were calculated in mmol trolox equivalent/L (9).

Measurement of total oxidant levels (TOS). On the $22^{\text {nd }}$ day of the trial, serum total oxidant levels were also measured using commercially available diagnostic kits (RelAssay, Gaziantep, Turkey). In this study, hydrogen peroxide $\left(\mathrm{H}_{2} \mathrm{O}_{2}\right)$ was used as the standard and the results were calculated in $\mu$ mol $\mathrm{H}_{2} \mathrm{O}_{2}$ equivalent $/ \mathrm{L}(8)$.

Oxidative stress index. OSI was defined as the ratio of TOS to TAS. For calculations, the TAS units were converted to $\mathrm{mmol} / \mathrm{L}$, and OSI was calculated according to the following formula: OSI (arbitrary units) $=\operatorname{TOS}\left(\mu \mathrm{mol} \mathrm{H}_{2} \mathrm{O}_{2}\right.$ equiv/L)/TAS (mmol Trolox equiv/L) $(8,9)$.

Relative testis weight. On day 22 of the study, after the body weights of the animals were measured and recorded, the rats were administered with a combination of ketamine $(90 \mathrm{mg} / \mathrm{kg})$ and xylazine hydrochloride $(10 \mathrm{mg} / \mathrm{kg})$ by intraperitoneal route, and were killed by cervical dislocation. Immediately after the euthanasia of the animals, their testes were excised and testis weights were recorded. The relative testis weight (testis weights/body weight $\times 100$ ) was calculated for each rat included in the treatment and control groups (29).

Sperm quality analysis. From the collected spermatozoa samples, the cauda region of the epididymis was minced in phosphate-buffered saline (PBS) at $37^{\circ} \mathrm{C}$. Sperm quality was assessed on the basis of four parameters: sperm concentration, sperm motility, membrane integrity and sperm DNA fragmentation. Sperm concentration was determined with the haemocytometer method (23). Sperm suspensions obtained from the cauda epididymis were diluted $1: 200$ with PBS and transferred into microcentrifuge tubes. Diluted samples were loaded into the counting chamber, and spermatozoa were counted with the aid of an improved doubleruled Neubauer haemocytometer under a light microscope. Sperm concentrations were expressed as $\times 10^{6} \mathrm{ml}^{-1}$. Aver- 
age sperm motility was determined by counting motile and nonmotile spermatozoa and was expressed as percent motility (4). Sperm membrane integrity was assessed using a fluorescent 'live/dead kit' (Molecular Probes, Eugene, OR, USA) containing propidium iodide (PI) and SYBR-14. Diluted sperm was first added $5 \mu \mathrm{L}$ of SYBR-14 kept at $38.5^{\circ} \mathrm{C}$ for 5 minutes, and then added $5 \mu \mathrm{L}$ of propidium iodide (PI). Five minutes later, $3 \mu \mathrm{L}$ of each sample was placed onto a glass slide, covered with a coverslip, and 100 spermatozoa were counted under an OLYMPUS BX51 fluorescent microscope (4). Sperm which showed red fluorescence when stained with PI, were considered non-viable, while those which showed green fluorescence when stained with SYBR-14 red were considered viable. Sperm DNA fragmentation was assessed in samples that were processed as described in the protocol of the Sperm-Halomax-Mus kit (Halotech DNA, Madrid, Spain). Accordingly, sperm presenting with large, spotty halos of chromatin dispersion were considered to have fragmented DNA, while those with small, compact halos of chromatin dispersion were considered not to have any DNA fragmentation. The groups were compared according to the DNA Fragmentation Indices (DFI) calculated. In order to determine acrosomal integrity, sperm samples of the treatment and control groups were smeared onto microscopic slides and air-dried. After being fixed with 99\% methanol the specimens were maintained at room temperature until fluorescence staining. The slides, which were incubated with $20 \mu \mathrm{g} / \mathrm{mL}$ of Alexa Fluor-488PNA (peanut agglutinin) conjugate (Molecular Probes, Eugene, OR, USA) at $37^{\circ} \mathrm{C}$ for 30 minutes for staining, were washed in PBS and examined under an epifluorescence microscope (Zeiss Axiophot, Oberkochem, Germany) using an appropriate filter set. The images of rat spermatozoa that were stained with Alexa Fluor-488-PNA were categorized under two groups. Intensive and moderate fluorescence in the acrosomal region was considered as an indication of an intact acrosome, whereas spermatozoa with weak, patchy, or no fluorescence in the acrosomal region were considered to have a damaged acrosome.

Histopathology. Following the euthanasia of the rats, the right testis was excised in all of the groups. After being fixed in 10\% formol, dehydrated in a graded series of ethanol and embedded in paraffin, the testicular tissue samples underwent standard procedures for hematoxylin and eosin staining. These samples were examined for inflammation, fibrosis, necrosis, degeneration, and hypospermatogenesis. The mean diameter of the seminiferous tubules was calculated by measuring the diameter of 12 round seminiferous tubules in each group with the aid of a 20X lens and an ocular micrometer using image analyzer Leica (DMLB) and Leica Qwin software. The diameter of the seminiferous tubules was measured across the minor and major axes, and the mean diameter was obtained.
Statistical analyses. All data are expressed as the mean \pm standard error of means (SEM). Differences were regarded as significant when $\mathrm{P}<0.001$. The statistical analyses of the spermatological and biochemical parameters were performed with analysis of variance (one-way ANOVA) and the Tukey's HSD test using the IBM SPSS Statistics (Version 20) software program.

\section{Results and discussion}

In this study, no side effects were observed such as diarrhea, lethargy, emesis, dermatitis and allergic reactions. It was observed that the animals included in all of the nickel groups displayed an decrease in feed intake and weakening, when compared to the nickel+bromelain group.

Relative testis weight and seminiferous tubule diameters. Although the bioaccumulation of nickel in the testes has been well demonstrated, the underlying mechanisms of nickel toxicity in the male reproductive system remain unclear (21). Similarly, the macroscopic findings obtained in the present study after nickel exposure by the intraperitoneal route revealed cyanosis in the testes, which showed that the testes were an accumulation site and target organ of this toxic metal (Fig. 1B). Macroscopic examination revealed distinctly oedematous and purple coloured testes in the group that was given nickel sulphate alone, and significantly

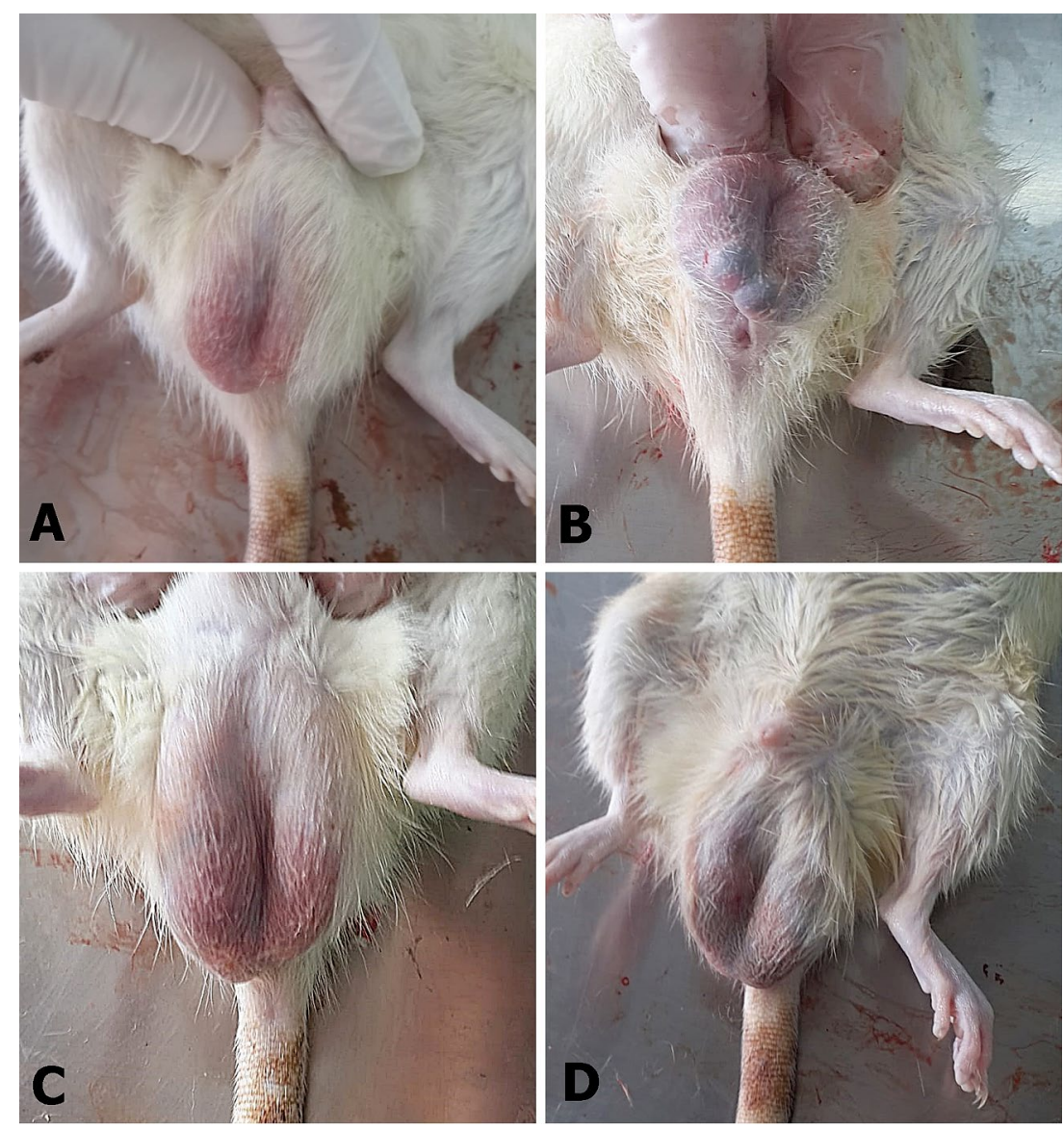

Fig. 1. Macroscopic appearance normal of scrotum from healthy control group (A) nickel group: cyanosis of the skin on the scrotum (B) bromelain group: normal scrotum $C$ ) nickel+bromelain group: slightly cyanosis of the skin on the scrotum (D) 
reduced cyanosis in the group that was administered with nickel sulphate+bromelain (Fig. 1D). In the group which received bromelain alone, no macroscopic alteration was detected in any of the testes, and the appearance of the testicular tissue was similar to that in the Tab. 1. Investigated sperm parameters in the different studied groups $(\overline{\mathbf{x}} \pm \mathrm{SE} ; \mathbf{n}=10)$

\begin{tabular}{|l|r|r|r|r|}
\hline \multicolumn{1}{|c|}{ Variables } & \multicolumn{1}{c|}{ Group I } & \multicolumn{1}{c|}{ Group II } & \multicolumn{1}{c|}{ Group III } & \multicolumn{1}{c|}{ Group IV } \\
\hline MTD $(\mu \mathrm{m})$ & $244.40 \pm 0.90^{\mathrm{a}}$ & $205.50 \pm 0.74^{\mathrm{b}}$ & $243.30 \pm 1.06^{\mathrm{a}}$ & $219.80 \pm 1.47^{\mathrm{c}}$ \\
RTW $(\mathrm{g})$ & $2.08 \pm 0.04^{\mathrm{a}}$ & $0.98 \pm 0.03^{\mathrm{b}}$ & $2.21 \pm 0.03^{\mathrm{c}}$ & $1.57 \pm 0.03^{\mathrm{d}}$ \\
\hline Sperm cell conc. (millons/mL) & $73.17 \pm 0.65^{\mathrm{a}}$ & $25.74 \pm 3.09^{\mathrm{b}}$ & $90.24 \pm 1.38^{\mathrm{c}}$ & $46.58 \pm 1.79^{\mathrm{d}}$ \\
Viability (\%) & $83.40 \pm 0.81^{\mathrm{a}}$ & $25.10 \pm 1.29^{\mathrm{b}}$ & $83.30 \pm 0.72^{\mathrm{a}}$ & $42.40 \pm 1.00^{\mathrm{c}}$ \\
\hline Abnormalities (\%) & $13.80 \pm 0.55^{\mathrm{a}}$ & $33.00 \pm 0.56^{\mathrm{b}}$ & $13.80 \pm 0.39^{\mathrm{a}}$ & $25.40 \pm 0.60^{\mathrm{c}}$ \\
Sperm motility (\%) & $82.50 \pm 0.83^{\mathrm{a}}$ & $24.50 \pm 1.17^{\mathrm{b}}$ & $83.50 \pm 0.76^{\mathrm{a}}$ & $40.50 \pm 0.89^{\mathrm{c}}$ \\
\hline Sperm DNA fragmentation rate $(\%)$ & $3.20 \pm 0.20^{\mathrm{a}}$ & $14.70 \pm 0.37^{\mathrm{b}}$ & $3.00 \pm 0.21^{\mathrm{a}}$ & $9.40 \pm 0.27^{\mathrm{c}}$ \\
\hline
\end{tabular}

Explanations: $\mathrm{a}, \mathrm{b}, \mathrm{c}, \mathrm{d}-$ means with different superscript letters differ significantly at $\mathrm{p}<0.001$; MTD - tubular diameter of seminiferous tubulus, RTW - relative weight of testes

control group (Fig. 1A, C). In addition, body weightorgan weight coefficients and histopathological findings are considered as sensitive indicators for the detection of toxicity in male reproductive organs (13). As observed in previous research and in the present study, nickel causes significant damage to leydig cells, sertoli cells, and germ cells and reduces both the weight indices of the testes and the diameter of the seminiferous tubules (Tab. 1). Nickel has been shown to pass through the blood testes barrier (1) and it has been suggested that it may cause germ cell degeneration, when accumulated in the testes (22). The comparison of seminiferous tubule diameters and relative testis weights revealed statistically significant differences between the groups $(\mathrm{P}<0.001)$. Seminiferous tubule diameters and testis weight indices had significantly decreased in the nickel group, and were significantly higher in the nickel+bromelain group, when compared to the group that received nickel alone. The seminiferous tubule diameter and the relative testis weight of the animals which received bromelain alone were similar to those of the control group (Tab. 1).

Sperm quality. Germinal epithelial damage resulting in azoospermia or oligospermia is known to be a consequence of treatment with toxic chemicals. Previous studies carried out in rodents have shown that excessive exposure to nickel compounds may lead to the accumulation of nickel in the testes, and thus decrease sperm counts, sperm motility and spermatogenesis while generating abnormal spermatozoa and causing testicular damage $(21,22)$. On the other hand, some researchers (6) have detected normal sperm counts, suggesting no adverse effect on sperm production. The results of the present study clearly demonstrate that while nickel exposure reduces sperm motility, sperm counts and viable sperm percentage, it increases the sperm DNA fragmentation index and percentage of abnormal spermatozoa, and thereby adversely affects sperm quality. When compared to the control group, the nickel group presented a decreased sperm count, and the bromelain group stood out with the highest sperm count. The sperm count of the nickel+bromelain group was lower than that of the control group, but higher than that of the nickel group (Tab. 1). These alterations may have differed with the dose and period of administration of nickel (5). The spermatozoa in the epididymis may have absorbed nickel very rapidly, eventually resulting in a negative impact on sperm quality. The alterations observed in the epithelial lining of the cauda epididymis may have affected sperm motility (22). Reduced sperm motility may have resulted from an increase in the number of abnormal spermatozoa. Thus abnormal spermatozoa percentage could be negatively correlated with sperm motility (23). In the nickel group, sperm motility and the percentage of viable sperm were significantly lower, while the percentage of abnormal spermatozoa and sperm DNA fragmentation were higher (Tab. 1). In comparison to the nickel group, the group that received both nickel sulphate and bromelain displayed higher sperm motility and viable sperm percentage and lower abnormal sperm counts and sperm DNA fragmentation rate. When compared to the control group, the bromelain group showed higher sperm motility and viable sperm percentage, yet this difference was found to be statistically insignificant. On the other hand, the abnormal spermatozoa percentage and sperm DNA fragmentation rate of the bromelain group were similar to those of the control group. The reduced sperm motility and increased sperm DNA damage levels detected in the nickel group may have resulted from the reactive oxygen species (ROS) generated by the leukocytes found in the sperm.

Testicular histopathology. While sperm are well protected in the microenvironment of the Sertoli cells in the testes, due to slow transfer and prolonged storage they are more vulnerable to the oxidant environment in the epididymis (6). In normal testes, the seminiferous tubules show a compact arrangement associated with a well-developed germinal epithelium and the presence of sperm cells in each tubule. Histopathological examination demonstrated that in the nickel group degeneration of the testicular tissue was more distinct and damage was greatest in the germ cells and Sertoli cells. The nickel group showed shrinking, buckling and disorganisation of the seminiferous tubules, as well as sloughing and vacuolation of the germinal epithelium of the tubules. Likewise the nickel+bromelain group presented germ cell disorganization and necrotic cellular debris in the seminiferous tubules, yet these findings 


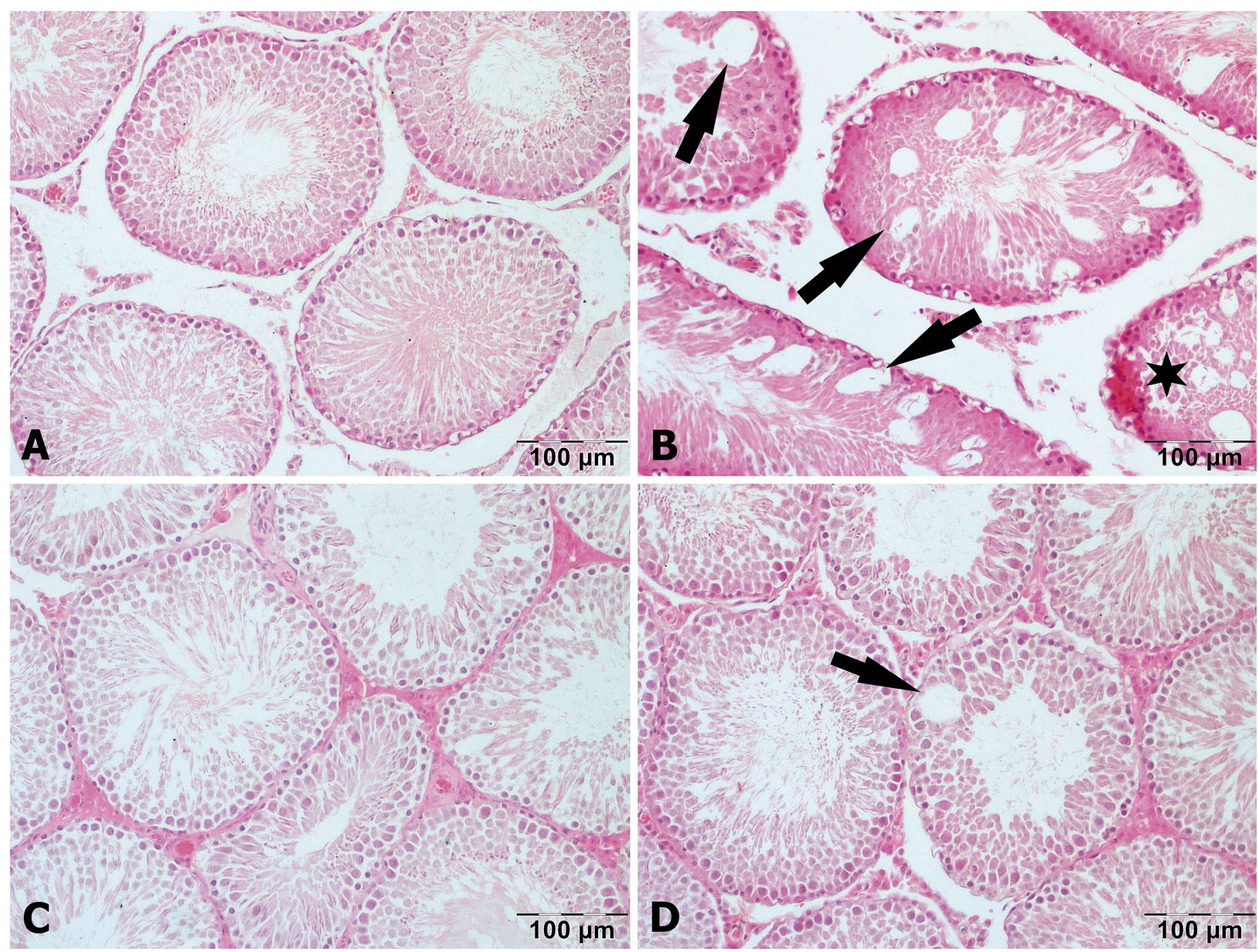

Fig. 2. Photomicrographs of rat testes stained by haematoxylin-eosin (HE). Section of control rat testes showing normal seminiferous tubules (A) nickel group: intense necrosis (star) and detachment (arrows) of seminiferous tubules (B) bromelain group: normal seminiferous tubules $(C)$ nickel+bromelain group: mild necrosis and detachment in of seminiferous tubules (arrow) (D) (magnification $40 \times$ )

were less extensive than that in the nickel group. In the nickel+bromelain group, both normal and damaged seminiferous tubules were observed in the testicular tissue. The light microscopic examination of the tissue sections belonging to the bromelain group showed that the seminiferous tubules had maintained a regular structure similar to that observed in the control group (Fig. 2).

Oxidative stress parameters. In the present study, nickel exposure increased sperm DNA fragmentation and reduced antioxidant levels. Our data agree with previous studies on nickel-induced DNA fragmentation in in vitro cell models $(11,25)$ and the rat liver $(30)$. Although the underlying mechanism of nickel-induced DNA damage remains unclear, the findings of the present study suggest that nickel-induced damage of sperm DNA and testicular toxicity could be related to the increased generation of reactive oxygen species and the oxidative damage of macromolecules. The mean TOS level of the nickel group was higher than that of the control group, while its TAS level was lower. The total antioxidant status (TAS) levels of the control and nickel groups were determined to be $2.96 \pm 0.15$ and $1.06 \pm 0.02$, respectively. Furthermore, the TAS levels of the nickel+bromelain and bromelain groups were $3.80 \pm 0.30$ and $5.69 \pm 0.18$, respectively. The total oxidant status (TOS) was found to be $28.48 \pm 1.79$ in the control group, $72.09 \pm 6.51$ in the nickel group, $45.68 \pm 3.02$ in the nickel+bromelain group, and 12.94 \pm 1.10 in the bromelain group. The present results show that while the TOS and OSI levels of the nickel group were higher than those of the control group, the TAS level was lower. OSI was higher in the nickel group, indicating the impairment of the system in favor of oxidants. OSI is an indicator parameter of the degree of oxidative stress level (31) and can demonstrate that nickel causes oxidative stress. The TOS and OSI levels of the nickel+bromelain group were lower than those of the nickel group; on the other hand, the TAS level was higher. The lowest TOS and OSI levels and highest TAS levels were detected in the bromelain group (Tab. 2). The low TOS and OSI levels and the high TAS level detected in the group, which was given bromelain alone, suggest that bromelain can be given to healthy 
animals as an antioxidant and can be effective in increasing the total antioxidant capacity. The administration of bromelain to nickel-intoxicated rats was found to alleviate nickel-induced testicular damage, improve oxidative stress parameters and sperm quality, and protect sperm DNA. To our knowledge, this is the first report demonstrating a decrease in nickel-induced sperm DNA damage and oxidative stress with the administration of bromelain. In this study, bromelain, which was used for prophylactic purposes, may have shown an antioxidant effect by reducing the generation of free oxygen radicals, and may have reduced the deleterious effects of nickel on sperm quality and testicular tissue. Bromelain is considered to have shown an antioxidant capacity in the detoxification of nickel, which causes severe structural damage to testicular tissue by binding to it.

In conclusion, nickel was shown to adversely affect the reproductive function by reducing sperm quality, inducing testicular damage, and increasing oxidative stress and sperm DNA damage. The exogenous administration of bromelain, which eliminates the adverse effects of nickel that causes severe structural damage to the testicular tissue, was observed to produce a protective effect. Bromelain may improve reproductive parameters in male rats exposed to nickel, and can be used as a potent natural product in clinical practice to avoid testicular damage and maintain sperm quality.

\section{References}

1. Al-Otaibi W. R., Virk P., Elobeid M.: Ameliorative potential of stem bromelain on lead-induced toxicity in wistar rats. Acta. Biol. Hung. 2015, 66, 149-160.

2. Bouhalit S., Kechrid Z., Elfeki A.: Effect of silymarin extracted from Silybum marianum on nickel hematotoxicity and nephrotoxicity in male albino wistar rats. Int. J. Pharm. Sci. 2017, 9, 84-89.

3. Calogero A. E., Condorelli R. A., Russo G. I., La Vignera S.: Conservative nonhormonal options for the treatment of male infertility: Antibiotics, antiInflammatory drugs, and antioxidants. BioMed. Res. Int. 2017, 4650182.

4. Cebi-Sen C., Yumusak N., Atilgan H. I., Sadic M., Koca G., Korkmaz M.: The protective effect of melatonin on sperm quality in rat after radioiodine treatment. Andrologia 2018, e12962.

5. Das K. K., Dasgupta S.: Effect of nickel sulfate on testicular steroidogenesis in rats during protein restriction. Environ. Health Perspect. 2002, 110, 923-926.

6. Doreswamy K., Shrilatha B., Rajeshkumar T., Muralidhara M. G.: Nickelinduced oxidative stress in testis of mice: evidence of DNA damage and genotoxic effects. J. Androl. 2004, 25, 996-1003.

7.El-Habit O. H., Abdel Moneim A. E.: Testing the genotoxicity, cytotoxicity, and oxidative stress of cadmium and nickel and their additive effect in male mice. Biol. Trace. Elem. Res. 2014, 159, 364-372.

8. Erel $O$.: A new automated colorimetric method for measuring total oxidant status. Clin. Biochem. 2005, 38, 1103-1111.

9. Erel $O$.: A novel automated direct measurement method for total antioxidant capacity using a new generation, more stable ABTS radical cation. Clin. Biochem. 2004, 37, 277-285.

10. Guo H., Cui H., Fang J., Zuo Z., Deng J., Wang X., Zhao L., Chen K., Deng J. Nickel chloride $\left(\mathrm{NiCl}_{2}\right)$ in hepatic toxicity: apoptosis, $\mathrm{G} 2 / \mathrm{M}$ cell cycle arrest and inflammatory response. Aging (Albany) 2016, 8, 3009-3027.

11. Kawanishi S., Inoue S., Yamamoto K.: Site specific DNA damage by nickel (II) ion in the presence of hydrogen peroxide. Carcinogenesis 1989, 10, 2235 -2238 .
12. Kechrid Z., Dahdouh F., Djabar R. M., Bouzerna N.: Combined effect of water contamination with cobalt and nickel on metabolism of albino (wistar) rats. J. Environ. Health Sci. Eng. 2006, 3, 65-69.

13. Kong L., Tang M., Zhang T., Wang D., Hu K., Lu W., Wei C., Liang G., Pu Y. Nickel nanoparticles exposure and reproductive toxicity in healthy adult rats. Int. J. Mol. Sci. 2014, 15, 21253-21269.

14. Lukac N., Massanyi P., Krockova J., Toman R., Danko J., Stawarz R., Formicki G.: Effect of nickel on male reproduction. Univers. J. Agric. Res. 2014, 2, 250-252.

15. M'Bemba-Meka P., Lemieux N., Chakrabarti S. K.: Role of oxidative stress, mitochondrial membrane potential, and calcium homeostasis in nickel sulfateinduced human lymphocyte death in vitro. Chem. Biol. Interact. 2005, 156 , 69-80.

16. Mahmoud K. E., Shalahmetova T. M., Deraz S., Umbavev B. A.: Combined effect of vanadium and nickel on lipid peroxidation and selected parameters of antioxidant system in liver and kidney of male rat. Afr. J. Biotechnol. 2011, 10, 18319-18325.

17. Massanyi P., Lukac N., Zemanova J., Zuo Z., Deng J., Wang X., Zhao L., Chen $K$., Deng J.: Effect of Nickel Administration in vivo on the Testicular Structure in Male Mice. Acta Vet. Brno 2007, 76, 223-229.

18. Mialovyts'ka O. A.: Effect of phlogenzym in long-term treatment of patients with multiple sclerosis. Lik. Sprava (In Ukrainian) 2003, 109-113.

19. Milic N., Milanovic M., Kon S. G., Milosevic N.: Current experience and future perspectives of bromelain application in medicine. Med. J. (Krag) 2014, 48, $153-158$

20. Murawska-Cialowicz E., Bal W., Januszewska L., Zawadzki M., Rychel J., Zuwala-Jagiello J.: Oxidative stress level in the testes of mice and rats during nickel intoxication. Sci. World J. 2012, 1-5.

21. Obone E., Chakrabarti S. K., Bai C., Malick M. A., Lamontagne L., Subramanian K. S.: Toxicity and bioaccumulation of nickel sulfate in SpragueDawley rats following 13 weeks of subchronic exposure. J. Toxicol. Environ. Health A. 1999, 57, 379-401.

22. Pandey R., Kumar R., Singh S. P., Saxena D. K., Srivastava S. P.: Male reproductive effect of nickel sulphate in mice. BioMetals 1999, 12, 339-346.

23. Pandey R., Srivastava S. P.: Spermatotoxic effects of nickel in mice. Bull. Environ. Contam. Toxicol. 2000, 64, 161-167.

24. Pari L., Amudha K.: Hepatoprotective role of naringin on nickel-induced toxicity in male Wistar rats. Eur. J. Pharmacol. 2011, 650, 364-370.

25. Patierno S. R., Costa M.: DNA-protein-cross links induced by nickel compounds in intact cultured mammalian cells. Chem. Biol. Interact. 1985, 55, 75-79.

26. Pavan R., Jain S., Shraddha., Kumar A.: Properties and therapeutic application of bromelain: A review. Biotechnol. Res. Int. 2012, 976203.

27. Rathnavelu V., Alitheen N. B., Sohila S., Kanagesan S., Ramesh R.: Potential role of bromelain in clinical and therapeutic applications (Review). Biomed. Rep. 2016, 5, 283-288

28. Sahbaz A., Aynioglu O., Isik H., Ozmen U., Cengil O., Gun B. D., Gungorduk K. Bromelain: A natural proteolytic for intra-abdominal adhesion prevention. Int. J. Surg. 2015, 14, 7-11

29. Sahinturk V., Guclu C., Baycu C.: Protective effects of vitamin E on ethane dimethane sulfonate-induced testicular toxicity in rats. Asian. J. Androl. 2007, 9, 117-124.

30. Stinson T. J., Jaw S., Jeffery E. H., Plewa M. J.: The relationship between nickel chloride-induced peroxidation and DNA strand breakage in rat liver. Toxicol. Appl. Pharmacol. 1992, 117, 98-103.

31. Yirun M. C., Unal K., Altunsoy S. N., Yirun O., Aydemir C., Goka E.: Evaluation of oxidative stress in bipolar disorder in terms of total oxidant status, total antioxidant status, and oxidative stress index. Arch. Neuropsychiatry 2016, 53, 194-198.

32. Zou L., Su L., Sun Y., Han A., Chang X., Zhu A., Liu F., Li J., Sun Y.: Nicke sulfate induced apoptosis via activating ROS-dependent mitochondria and endoplasmic reticulum stress pathways in rat Leydig cells. Environ. Toxicol. 2017, 32, 1918-1926

Corresponding author: Dr. Cigdem CEBI SEN, Department of Reproduction and Artificial Insemination, Harran University, Faculty of Veterinary Medicine, 63100 Sanliurfa, Turkey; e-mail: cigdemcebi@hotmail.com 